\title{
Teaching Phonetics Using A Mobile-Based Application in an EFL Context
}

\author{
Haggag Mohamed Haggag (Phd) \\ Lecturer of Curricula and TEFL Methodology \\ Hurghada Faculty of Education, South Valley University, Egypt
}

Doi: 10.19044/esj.2018.v14n14p189 URL:http://dx.doi.org/10.19044/esj.2018.v14n14p189

\begin{abstract}
Mobile based learning has been an effective mean for learning languages. The aim of this study is three-fold: first, to investigate the process of designing mobile-based application for teaching phonetics in EFL context. The second is to verify the effect of this mobile application on pre-service EFL teachers' achievement of English phonetics at a university level. Finally, it aims to investigate participants' satisfaction towards Mobile Assisted Language Learning. The research implements a mobile based program for developing preservice teachers' segmental elements in a phonetics courses. It deals with how to design the program, implement it and test its results. Participants of the study were (23) pre-service English language teachers at Hurghada Faculty of Education, South Valley University, Egypt. Instruments of the study included a mobile based phonetics module, English phonetics achievement Test and an English Satisfaction scale. Results showed a development in participants' achievement at the level (0.01) in mastering the segmental elements (Phonemes identifications- consonants classificationvowels classification). Participants showed their satisfaction of the application through their positive feedback and responses to the items of the questionnaire.
\end{abstract}

Keywords: Mobile Learning- phonetics - Satisfaction - EFL

\section{Introduction}

Deploying Mobile-based technology for the purpose of foreign language learning is unavoidable. According to Kukulska-Hulme et al. (2011), in education, Mobile Learning, is a term that refers to the use of mobile technologies for educational purposes. These devices can offer learning opportunities that are: spontaneous, informal, contextual, portable, ubiquitous, pervasive, and personal. Mobile Assisted Language Learning MALL or Mobile Learning ML in the field of language pedagogy refers using any sort of mobile technologies for learning a language. This wave of ML arouse from 
the fact that desktop computers have become indispensable for the new generation due to the amount of information, learning challenges and telecommunications vast developments.

Benefits of using mobiles in classrooms (Thomas \& O'Bannon: 2014) are various. They include effective student engagement, enhancing content creation, student centeredness, authentic learning and reflection. Benefits of mobile learning have been highlighted by many studies (see Gerger, 2017, Boticki et. al. 2015, Lu et al., 2015). These benefits include allowing students to take control of their learning (autonomy), managing their self-directed learning, participating both the design and instruction of the courses.

Teaching phonetics using mobile devices has been used in various studies due to its positive impacts. These studies can be classified into (a) studies that used a mobile device (e.g. Thomas\& O'Bannon (2015), Okunbor \& Retta (2005), Begum (2011), Soliman \& Al-Turki (2012), Bevell \& O'Dwyer (2010) and Fleischer (2012). (b) Studies that dealt with a mobile software (e.g. Alemi, et al. (2012), Liu, et al. (2014), Xiao \& Luo (2015). These studies dealt with developing on or more than a language skill or a language area such as vocabulary or grammar.

The purpose of this study is to investigate the effect of using a mobile application designed by the researcher (named as HPhonetics, where $\mathrm{H}$ refers to author's first name) on phonetics achievement and identifying participants' satisfaction with mobile learning.

\section{Literature Review}

Mobile technology, such as tablets and smart phones has become popular worldwide with a broad range of users in classrooms, including students from all levels of education (Garante \& Domingo: 2016). This wide growth of both hardware and software that moved from PC programs to handheld mobile applications led to a need to design new curricula, pedagogy and assessments that support autonomous mobile-based learning. Mobile technology's positive impacts have been examined by various studies (see Ertmer, 2005, Murphy 2011,Gerger, 2014). These studies conclude that mobile technology encourages students to be active learners, facilitate their access to information, promotes collaborative learning, provides instant feedback and fosters autonomous learning. These impacts led to a new wave of Mobile Assisted Language Learning.

Mobile Assisted Language Learning MALL refers to the use of mobile technology in language leaning. It was defined by O'Malley et al. (20113:3) to mean "any sort of learning that happens when the learner is not in a fixed, predetermined location, or learning that happens when the learner takes advantage of the learning opportunities offered by mobile technologies". The term MALL first appeared in 1980s, when Xerox Palo Alto Research PARC 
developed the Dynabook, a device very similar to what it is known as a tablet. It then continued to emerge in the European education and Asian institutes (Cristina, Jorge, Pilar \& Arancon: 2013).The use of handheld devices instead of PCs and computers led to positive advancements in language learning pedagogy.

The widespread of mobile technologies which can execute many functions of desktop computers have become indispensable for the new generation (Cumaoglu \& Coskun, 2013). They further explained that students started to carry these technologies to the school environment. Although there are many studies that promote the use of mobile devices and technologies in language learning (e.g. see McCarten, J.: 2007, Jee, M. 2011, and Habbash:2013), many traditional learning environments in different parts of the world are still in support of keeping mobile phones switched off while students are in classes.

The studies that dealt with mobile learning in the field of Foreign Language Learning FLL can be divided into two main categories: first, studies that dealt with the use of a mobile device (e.g. smart phones, laptops, iPhones, iPads, tablets etc.) for the development of a language(s) skill. Second, studies that utilized a mobile software (e.g. application, gadget, program...etc.) for language development. In Teaching English as a Foreign Language Learning TEFLL, these studies aimed mainly to develop English language competence or performance. For instance, studies that used mobile devices both in EFL/ESL and English as First Language contexts aimed mainly to promote authentic and better practices of using mobile devices for the purpose of language learning. These devices included a variety of handheld and PC types such as handheld devices, smart phones, PC computers, laptops, MP3, MP4, notebooks, tablets, book readers and PDAs. For instance, Mobile Phones were used by Thomas \& O'Bannon (2015) in a study that examined the perceptions of (245) preservice teachers in Kentucky and Tennessee to determine their support for the use of mobile phones in the classroom, as well as their perceptions of the mobile phone features for school-related work. Results indicated that $(45 \%)$ of the participants supported the use of mobile phones in the classroom. Similarly, Liu, Chang \& Sung (2016) investigated the effect of integrating mobile devices in teaching and learning on students' learning performance. The study has run a meta-analysis and research synthesis of the effects of integrating mobile devices in teaching and learning. In this study, a number of (110) experimental and quasi experimental journal articles published during the period 1993-2013 were coded and analyzed. Results showed various aspects in using mobile devices and software for different ages and language purposes. It recommended elaborate instructional design advancements and enhancing both pedagogy and experimental design for mobile intervention. 
Mobile phones were used in various studies for language learning development. For instance, Okunbor \& Retta (2005) explored using mobile phones for language learning and found that students were able to manage their academic and social lives using mobile applications made by the service provider itself and made available to students on the national mobile phone network. Begum (2011) examined the prospect of Cell Phones as instructional tools in the EFL classroom using a case study in Jahangirnagar University in Bangladesh. Participants were (100) EFL students in Bangladesh and the study utilized questionnaires for the students and their class observation. Results showed that cell phones have great potentials as instructional tool despite some challenges in actual class practices. Soliman \& Al-Turki (2012) also examined Saudi students' acceptance of using mobile phones and handheld devices in language and learning. Results showed that students viewed mobiles useful in factors related to course materials access, information browsing, sharing knowledge and doing assignments.

Laptops use in language learning was a topic of research in many studies in EFL context.. Zucker \& Light (2009) investigated the effect of using laptops on students' learning development. Results of the study showed that laptops could develop students' higher thinking levels and transformation of classroom teaching methods. Similarly, Bebell \& O’Dwyer (2010) discussed using laptops in four researches and came up with conclusions that promote the use of laptops in one to one teaching g contexts, using laptops affects positively teachers' methods and that students still use laptops in writing and basic internet browsing internet in the first place. Laptops use was also investigated in a narrative research review of (18) different empirical studies by Fleischer (2012). The study concluded that teachers' beliefs about laptops use affect greatly their teaching practices.

Second category, software and mobile applications' studies, aimed to develop specific language area or skill(s) (see Thoronton and Houser (2005, Stockwell (2010), Wang \& Shih (2015). Vocabulary development, for instance, was an area of study using SMS/MMS-based experiments and programs. Suwantarathip \& Orawiwatnakul (2015) experimentally compared the effect of in-class paper based vocabulary exercises with SMS messages sent to students outside the class for new vocabulary development. The study lasted for 6 weeks. Results showed that the experimental group had significant mean differences greater than the control group. Similarly, Alemi, et al. (2012) examined the use of SMS in language knowledge in two groups, although the results showed no mean differences between the two groups in language knowledge, still the experimental group was more successful in the follow up test. Results also showed that participants had positive attitudes towards the use of SMS in English vocabulary development. 
Liu, et al. (2014) used iPod Touch as a teaching and learning tool. The study examined how EFLL teachers and their students used this tool to enhance their teaching and learning. Despite the difficulties encountered in applying this learning tool (e.g. time frame, software and measurement), results showed that the tool was effective and useful for ELL instruction, improving learning capacity and bringing forward unique affordances for learners.

Studies that dealt with teaching phonetics courses using mobile applications are different according to the phonetic areas and applications types. According to Xiao \& Luo (2015:1) "Phonetics is an essential part of foreign language learning, with the help of mobile technologies, mobile learning has developed into a new mode of learning". In their study (ibid) about application of mobile learning system in phonetics teaching, they concluded that mobile application (named Liulishu) can enrich the teaching of phonetics in EFL context. In a quasi-experimental design the researchers run a two-group experiment where the results of both control and experimental one are compared using phonetics test. Results showed that the latter group outperformed the control group due to the use of mobile application in phonetics teaching.

A study by Imam et al. (2014) aimed at developing ESL students' pronunciation through an interactive English pronunciation application. The study utilized a research and development method to design and implement a mobile application for improving English pronunciation. The application consisted of two mail pages (Sounds -Tests). Using the designed android application, participants could differentiate between the correct English pronunciation and their common errors. A similar study that dealt with only American stress by Bott (2005), examined the computer-based self -access pronunciation materials on EFL/ESL phonetic awareness and the stress. The study provided learners with computer-based materials, and then followed by tests to identify their progress. Results showed that drilling EFL/ESL students with self-accessed materials could develop their phonemic awareness and pronunciation skills. These results were achieved in a different EFL context by Dekaney's (2003). The study also promoted the use of computer-based activities for phonetic drilling.

Abu Seileek (2016) examined Computer-assisted Pronunciation Instruction software as effective means for teaching stress patterns. The study aimed at assessing the use of computer-based pronunciation instruction in enabling EFL learners in advanced English language classes at the university level to perceive and produce the correct stress patterns. Using the communicative approach, the study provided meaningful, interactive, and authentic activities for pronunciation development. Results showed that computer-assisted pronunciation instruction is effective in improving the EFL 
learners' ability to produce and perceive correctly different stress patterns in words, phrases, and sentences. Results also showed that students have a positive attitude toward computer-assisted pronunciation instruction software and activities.

Wilson (2016) examined the use of Praat software and Moodle for teaching segmental and suprasegmental pronunciation. Praat is open access pronunciation software and Moodle is an online platform for showing polling results for students' choices. The study mainly focused on teaching vowels and consonants. Results showed that students developed their phonetic awareness for both segmental features (consonant and vowels) and suprasegmental features (stress, rhythm and intonation).

In conclusion, Mobile Learning technology has been used for developing language areas or sub-skills in EFL contexts. In spite of the challenges and limitations, mobile learning has positive impacts on many language fields, including phonetics, which is the core of this research.

\section{Research Hypotheses}

1.1. There are statistically significant mean differences between the mean scores of the participants in the pre post testing of phonetics achievement favoring the post testing.

1.2. There are statistically significant mean differences between the mean scores of participants' satisfaction in the pre post measurements of the satisfaction scale favoring the posting test.

\section{Methodology}

The research follows the one group quasi-experimental design with its pre and post testing due to its nature. The following is a description for research participants, instruments and procedures of running the experiment.

\section{Participants}

The participants were group of EFL students (N.23) at Hurghada Faculty of Education, South Valley University, Egypt. They were selected based on their level of English (M 60) and their knowledge of mobile use for language learning.

\section{Delimitations}

The study was delimited to (1) Segmental features (vowels \& consonants) and sound articulators or organs of speech. (2) Free mobile application provider (Andromo). (3) A group of EFL students at Hurghada Faculty of Education (N.23), Egypt. (4) Participants were EFL students, who passed the test, interview, owe and use smart phones for learning and ready to volunteer in the study and attend regular lab sessions. 


\section{Instruments}

Instruments included the following (4) tools designed and developed by the researcher. To achieve, the aims of the research, validity of these tools was calculated using SPSS using the square root of the reliability values. Another validity method used was the jury validation where specialists at TEFL field reported their recommendations and final approval of the following instruments.

\section{Mobile use questionnaire: this tool aimed at and used for two purposes}

The first is to adjust the sample based on their knowledge of mobile use for the aim of language learning. The second is to identify their satisfaction with the module and the use of mobile application for learning English phonetics. Therefore, the questionnaire includes two parts; the first is Mobile Use and the second is Mobile and Language Learning.

\section{Phonetics Module}

Using a free android application (named Andromo), the researcher designed an application (HPhonetics) that contains two main pages (Segmentals and Articulators). Units and elements of the application were validated by a jury of EFL/Linguistics experts.

\section{Mobile-Based phonetics achievement test}

It aimed at identifying participants' knowledge of the segmental features and sound articulators. Validity of the test was calculated using SPSS based on the views of a jury of TEFL and Linguistics experts. Reliability was calculated using Split-Half statistics using SPSS and reported $(r=0.70)$. The test was uploaded online on (www.nearpod.com) and students had to poll over the test. This instrument was used to adjust the sample for the experiment in order to verify their ability to use the mobile based application for learning phonetics course.

\section{Students' Satisfaction Scale}

This instrument aimed to identify students' satisfaction and acceptance of the course with its outcomes. The questionnaire was designed and posted online to be completed by the students and to express their views and levels of satisfaction about the course and the application. To verify its validity, content validity was calculated by a jury of TEFL experts. Reliability using split-half method was calculated using SPSS ( $\mathrm{r}=0.78)$. The scale included (10) items and were divided into guided responses items and open-ended responses and it was upload online on (www.surveyomnkey.com) as in attachment (2). 


\section{Design}

Using thequasi-experimental one-group design, 98 participants volunteered for the study at Hurghada Faculty of Education. They were adjusted according to their knowledge of mobile use for language learning (using an interview), and their level of English (post intermediate), using an online English language test. Due to English lab acoustic as well as the results obtained from the test and interview, only (23) participants were selected. Students were instructed in 10 sessions ( 3 hours each). They were informed with the assessment plan (that included formative and summative assessments) and the type of quizzes and tests they have to pass. A phonetics test was used in a pre-post setting as well as an interview before and after the end of the course. Means in the pre and post tests were compared using SPSS statistical program.

\section{Results and Discussion}

Results from this research were obtained from three instruments; first is the achievement test in phonetics, second is the satisfaction questionnaire and the third is the feedback and reflection papers written by the participants. Results obtained from the pre post testing of phonetics test were analyzed using SPSS program. The following three tables indicate the descriptive values of the testing as well as the scores of mean differences analysis using T-test statistics.

Table (1) below describes the obtained descriptive data from the two testing Running, their means, minimum and maximum scores as well as the standard deviation.

Table (1) Descriptive Statistics for pre and post testing of phonetics test

\begin{tabular}{|c|c|c|c|c|c|}
\hline Testing & $\mathrm{N}$ & Minimum & Maximum & Mean & $\begin{array}{c}\text { Std. } \\
\text { Deviation }\end{array}$ \\
\hline Pre testing & 23 & 24 & 40 & 29.57 & 3.514 \\
\hline Post testing & 23 & 28 & 48 & 36.57 & 5.575 \\
\hline
\end{tabular}

The above table indicates scores of the participants in the pre and post testing. The table shows the minimum and maximum scores in the pre and posttests (min 24 and 28 and max are 40 and 48) respectively. The scores show the increase in participants' scores after the post testing. To verify the development in participants' mean scores the following statistic was run.

Table (2) One-Sample Statistics for phonetics Test

\begin{tabular}{|c|c|c|c|c|}
\hline Testing & $\mathrm{N}$ & $\begin{array}{c}\text { Std. Error } \\
\text { Mean }\end{array}$ & Std. Deviation & Mean \\
\hline Pre test & 23 & .733 & 3.514 & 29.57 \\
Post test & 23 & 1.162 & 5.575 & 36.57 \\
\hline
\end{tabular}


Table (2) shows means of the participants in the two tests. Pretest mean score is (29.57) and the post test is (36.57). These scores show the development in students' performance over the test favoring the post test. To identify the significance of this difference, the following measurement was run.

Table (3) Mean differences in the pre post testing of phonetics test

\begin{tabular}{|c|c|c|c|c|c|c|}
\hline \multicolumn{9}{|c|}{ Test Value $=0$} \\
\hline \multirow{3}{*}{ Testing } & & & & Mean & \multicolumn{2}{c|}{$\begin{array}{c}95 \% \text { Confidence } \\
\text { Interval of the } \\
\text { Difference }\end{array}$} \\
\cline { 2 - 7 } & Lower & Upper & Lower & Upper & Lower & Upper \\
\hline Pre test & 40.351 & 22 & .001 & 29.565 & 28.05 & 31.08 \\
Post test & 31.458 & 22 & .001 & 36.565 & 34.15 & 38.98 \\
\hline
\end{tabular}

Table (3) shows that there are significant mean differences between participants' scores in the pre posttests. Significance value (.001) shows that there are significant mean differences between the two tests favoring the post test. This difference is obvious in t-values (40.351 and 31.458) which are significant the level (0.1); these differences are attributed to the impact of the independent variable (the application in phonetics).

Second, results obtained from students' satisfaction questionnaire: since the questionnaire aims at identifying students' satisfaction and consent with the application and the experiment, items of the questionnaire were designed and analyzed for this aim. Results obtained from the questionnaire showed students' satisfaction and consent with the application and its content. The following figure (1) shows an analysis for their answers to question one" How likely is it that you would recommend HPhonetics software to your colleagues?" and the result shows their satisfaction.

Figure (1) students' responses to Q1

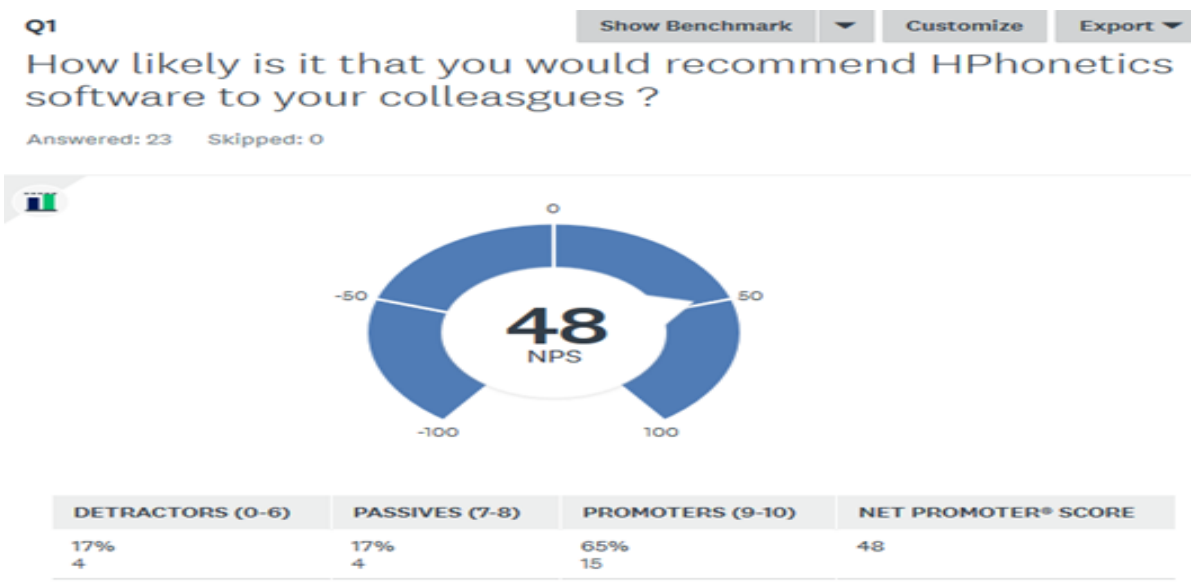


The above figure shows that the NET score as analyzed by the website (SurveyMonkey) shows that their satisfaction level is (48/50), which is a very high score. The following figure also shows students' satisfaction with the content and activities of the application as shown in Q3 results.

Figure (2): Students' responses to Q3

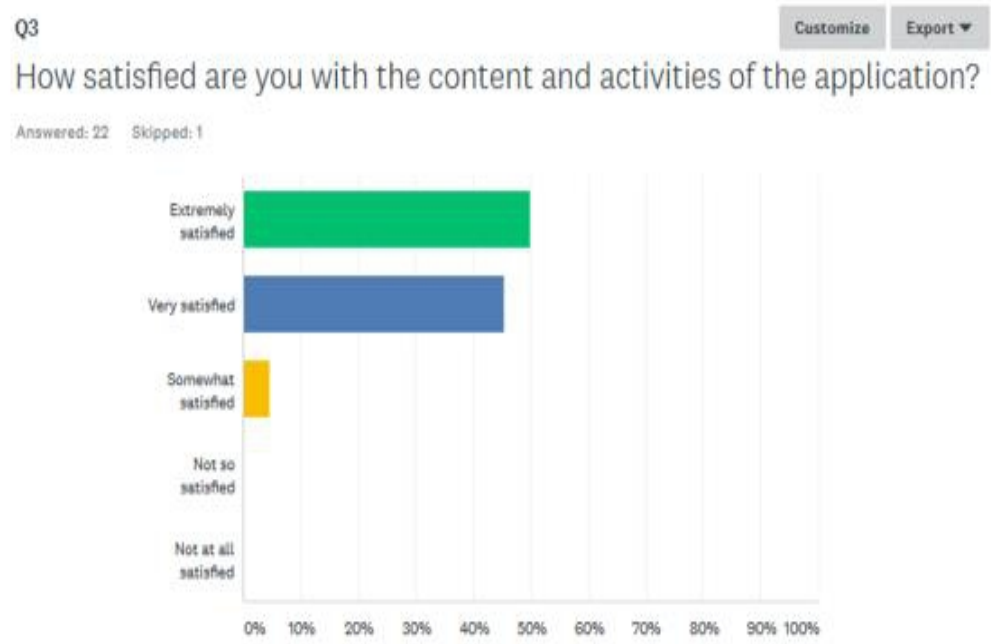

The above figure shows that students' satisfaction ranged from (extremely satisfied) and (very satisfied) with fewer responses in (somewhat satisfied). Another example of students' opinions is expressed in Q4 as the following figure (4) shows.

Figure (3): Students' responses to Q9

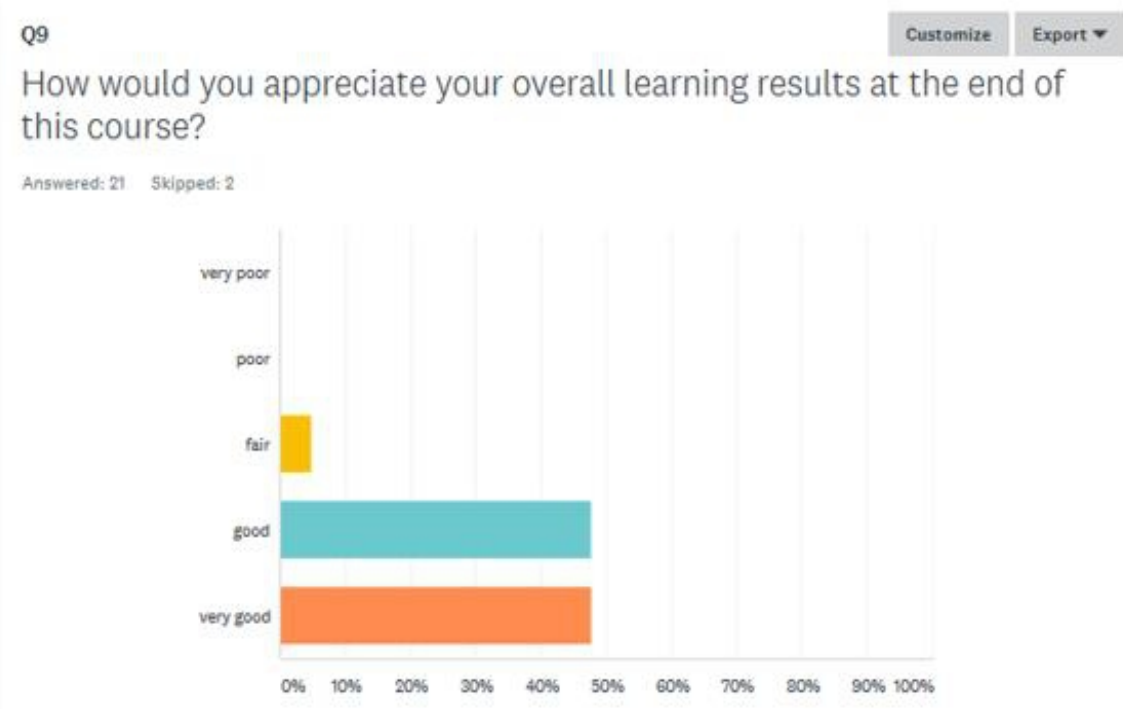


The above figure shows students' answers to the question about their appreciation of their overall results at the end of the course. Results showed that participants viewed their learning development to range from good to very good. Their comments and feedback included the following:

"I feel this program helps me to develop my English and now I can use it in transcription as well. The application can be shared with my study groups as well. My friends also liked it when they saw it while we were studying" (Shahinda Abol Ela, $4^{\text {th }}$ year senior student).

Another positive feedback by (Fatima Awad, $4^{\text {th }}$ year senior student) wrote "It has many sections and it included exercises as well. I can use it in studying the phonemes, consonants and vowels and the syllables. The program looks beautiful and colorful; I enjoyed it and will keep it on my mobile for study any time".

Feedback excerpts by students show the importance of the application to the students. It also shows their satisfaction with it. On the other hand a comment by one of the students showed her worries about using the program as follows:

"I liked the program but I feel I have to be connected to internet all time; it costs. I need to be connected whenever I use it". To solve this problem I need to use a prepaid application service to have it available without internet access in all its sections. Some of the sections can be opened without internet while others need to have access. This is because the application is free.

Results also showed that the participants recommended enhancements to the view of icons in the application as well as its technical outline (e.g. icons size, order and view). The researcher adapted these changes in the last update of the application. In sum, results obtained from this tool show participants' overall satisfaction with the application and content to develop their phonetic knowledge and skills about the English language.

In a teacher reflection view, the researcher- who instructed the coursefound that using HPhonetics application helped him in scheduling tasks, assignments, and announcements and for promoting an effective course assessment plan. It also helped him as an instructor of phonetics to communicate in a virtual extra-curricular setting.

\section{Conclusion and implications}

In a pre-postdating, the research examined the effectiveness of a mobile based software -HPhonetics- for developing participants" knowledge and skills in phonetics. The research utilized four main instruments, mobile use test, phonetics module, phonetics test and a satisfaction questionnaire. Results from the test showed there are significant mean differences $(0.001)$ between the pre and posttests favoring the post test. This shows a development in participants' performance in phonetics due to the use of the application. 
Another important result is their performance over the satisfaction questionnaire. Results showed that participants were satisfied with the application and the content to learn English phonetics and mainly the Segmentals.

Implications of this research in the light of the obtained results can be for students, course designers, teachers and assessment theory and practice. As to the students, using this type of mobile based learning (e.g. HPhonetics application), students can enjoy an extra-circular learning experiences with hand held applications in various language field not just phonetics. Students can do home practices, test and quizzes at home and at an environment out of the traditional class environment. As to teachers, they can use this software as a compulsory material or as a practical session requirement in a phonetics course. Teachers can use this mobile based phonetics module, test, questionnaire and attachments in their phonetics courses at a university level. As to course designers, this free app can be an example to integrate mobile applications in phonetics courses due to their advancements and availability to language learners. These free apps can be easily designed, tested and upgraded. Finally, the type of formative assessments (final phonetics test) as well as summative ones (quizzes and questionnaires) can be utilized in assessing phonetics courses at the university. Instructors and lectures can uses these tools during lectures and practical sessions.

\section{References:}

1. Abu Seileek, A. (2016). Computer-assisted Pronunciation Instruction: Learners' Preferences and its Effect on EFL Stress Acquisition. Available online, Retrieved: www. faculty.ksu.edu.sa/.../My\%20Paper\%20Computer-based, Last visit 25-9-2016

2. Alemi, M., Sarab, M. R. A., \&Lari, Z. (2012). Successful learning of academic word list via MALL: Mobile Assisted Language Learning. International Education Studies, 5 (6), 99-109. http://dx.doi.org/10.5539/lies.v5n6p99

3. Bebell, D. \& O'Dwyer, L. M. (2010). Educational outcomes and research from 1: 1 computing settings, Journal of Technology, learning and assessment, 9, 5-15. Retrieved from http://eournals.bc.edu/ojs/index/index.php/jtla/article/view/1606

4. Begum, R. (2011). Prospect of Cell Phones as instructional tools in EFL classroom: A case study of Jahangirnagar University, Bangladesh, Journal of English Language Teaching, 4 (1)

5. Bott, A. (2005). Computer-aided self-access pronunciation materials designed to teach stress in American English. Unpublished MA dissertation. Brigham: Brigham Young University. 
6. Christina, C., Jorge, A., Pilar \&Aracon, R. (2013). The use of current mobile learning applications in EFL. Retrieved : www.sciencedirect. Last visit $\{21-10-2016\}$

7. Cumaoglu, G. \& Coskun, Y. (2013). Scale of teachers' beliefs on the effect of the use of mobile devices on students. Journal of Social and Behavioral Science (106) - 2299-2306

8. Dekaney, E. (2003). The effect of computerized versus classroom instruction on the phonetic pronunciation of English. Journal of Research in Music Education, 51 (3), 206-217.

9. Ertmer, P.A. (2005). Teacher pedagogical beliefs: the final frontier in our quest for technology integration? Educational technology, Research and development, 53(4), 25-39

10. Fleischer, H. (2012). What is our current understanding of one to one computer projects: a systematic narrative research review, Educational research review, 7, 107-122. http://dx.doi.org/10.1016/j.edurev

11. Garante, A., B. \& Domingo, M., G. (2016). Exploring the use of educational technology in primary education: teachers' perception of mobile technology learning impacts and applications' use in the classroom. Journal of Computers in Human Behaviors. Retrieved from : www.elsevier.com/locate/comphumbeh, last visit \{22-10-2016\}

12. Gerger, K. (2014). 1:1 tablet technology implementation in the Manhattan Beach Unified School District: A case study . Long Beach: California State University

13. Habbash, M. (2015). Learning English vocabulary using mobile phones: Saudi Arabian EFL teachers in focus. European Scientific Journal, Vol. (11), N. (35)

14. Jee, M. (2011). Web 2.0 technologies meets mobile assisted language learning. The IALLT Journal of language learning technologies, 41 (1), 161-175

15. Imam, D. A., M. Pd., Hasbi, ,M., Kom, S., Aliv, F. M., Politeknik, E. 7 Jalan, R. (2014). Developing mobile application of interactive English pronunciation training to improve EFL students' pronunciation skill. Journal of Education and Practice, 5 (33)

16. Liu, M. Navarrete, C. C., Maradiegue, E. \&Wivagg, J. (2014). Mobile Learning and EnglishLanguage Learners: A Case Study of Using iPod Touch As a Teaching and Learning Tool. Journal of Interactive Learning Research. , 25(3)

17. Liu, T., Chang, K. \& Sung Y. T. (2016). The effects of integrating mobile devices with teaching and learning on students' learning performance: A meta-analysis and research synthesis. Computers and Education Journal, 94, 11 (252-275) 
18. McCarten, J. (2007). Teaching vocabulary: lessons from the corpus; lessons for the classroom. Cambridge University Press, NY, USA, Pp. 25

19. Murphy, G. D. (2011). Post-PC devices: a summary of early iPad technology adoption in tertiary environments. E-journal of Business Education \& Scholarship of Teaching, 5 (1), 18-32

20. Okunbor, D. \& Retta, G. (2008). Analysis of a mobile learning pilot study. Math and Computer Science, \{Online\}, Retrieved: http://digitalcommons.uncfsu.edu/macscwp/2, last visit \{21-10-2016\}

21. O’Malley, C., Vavoula, G., Glew, J., P., Taylor, J., Sharples, M. \&Lefrere, P. (2003). MOBIlearn WP4-Guidelines for learning/teaching/tutoring in a mobile environment. Retrieved : http://www.mobilearn.org/download/results/guidelines.pdf \{last visit 22-10-2016\}

22. Soliman, M. E. \& Al-Turki, M. S. (2012). Mobile learning adoption in Saudi Arabia. World Academy of Science, Engineering and technology, 69, 356-358

23. Stockwell, G. (2010). Using mobile phones for vocabulary activities: examining the effect of the platform. Language learning \& technology, $14(2), 95-110$

24. Suwantaratip, O. \&Orawiwantakul, W. (2015). Using mobile assisted exercises to support students' vocabulary skill development. Turkish online journal of educational technology, 14 (1), 163-171

25. Thomas, K. \& O'Bannon, B. (2015). Mobile phones in the classroom: Preservice teachers answer the call. Computers and Education Journal, 85 (110-122)

26. Thoronton, P. \& Houser, C. (2005). Using Mobile phones in English education in Japan., 21(3), 217-228. http://dx.doi.org/10.1111/j.13652729.2005.00129.x Journal of computer assisted learning

27. Xiao, J. \& Luo, Y. (2015). Application of mobile learning system in phonetics teaching. International conference on social science, Atlantis Press, China

28. Wilson, I. (2016). Using Praat and Moodle for teaching segmental and suprasegmental pronuniciation. Retrieved: http://http://web-ext.uaizu.ac.jp/ wilson/ Wilson2008World CALLProcLowRez.pdf , last visit 8-9-2016

29. Zucker, A. A., \& Light, D. (2009). Laptop programs for students, Science Journal. 323, 82-85. http://dx.doi.org/10.1126/science/1167705 


\section{Appendices}

1. Phonetics app layout screenshot

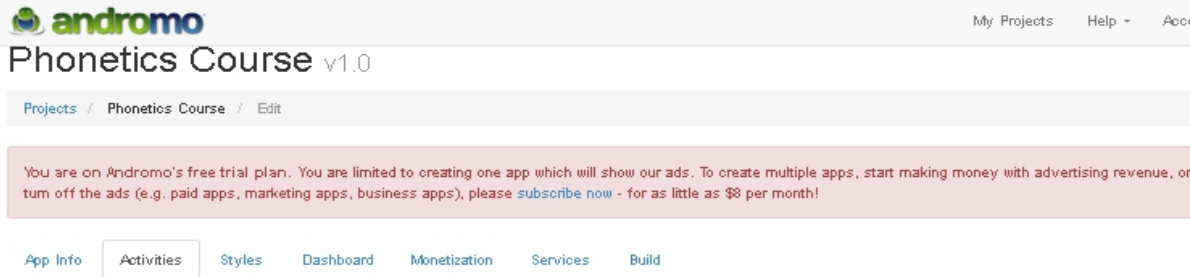

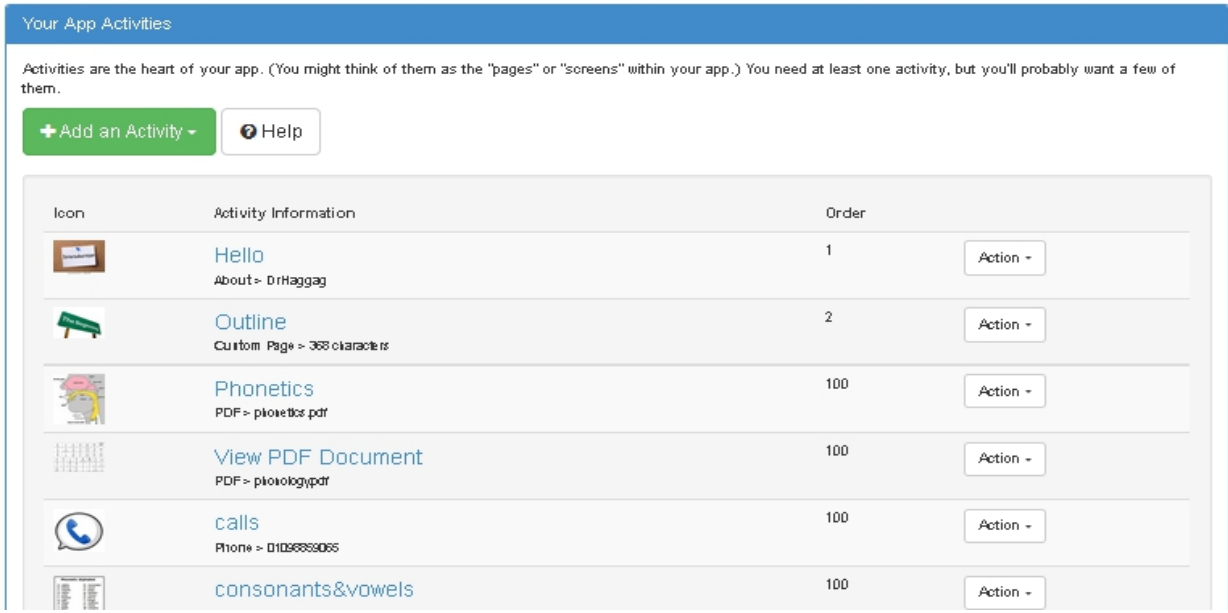

\section{Mobile use test link}

Available atNEARPOD website (www.nearpod.com):

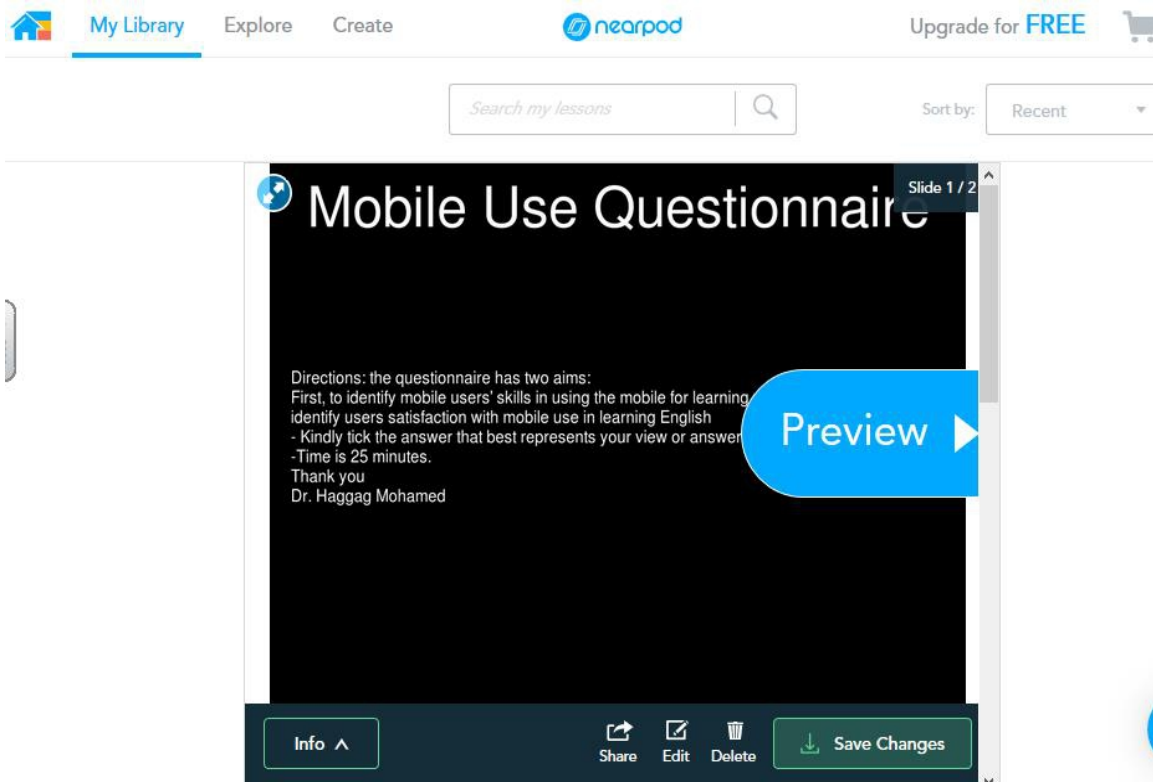




\section{Students' satisfaction questionnaire link}

Students' satisfaction questionnaire (Available online) at: https://www. surveymonkey.com/r/TX3DHRV

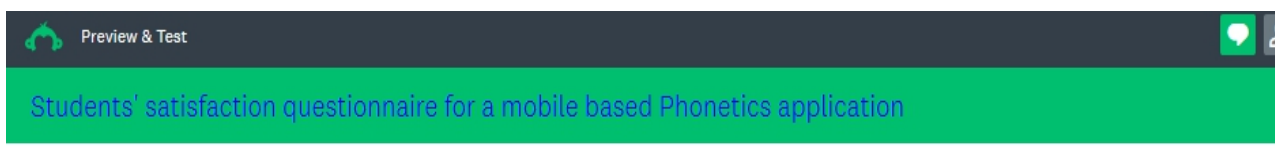

Students' satisfaction questionnaire for a mobile based Phonetics application

By Dr. Haggag Mohamed

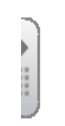

This questionnaire aims at identifying students' satisfaction about a mobile application for learning supra-
segmentals "HPhonetics application".

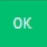

Phonetics test link

Available on NEARPOD website (www.nearpod.com)

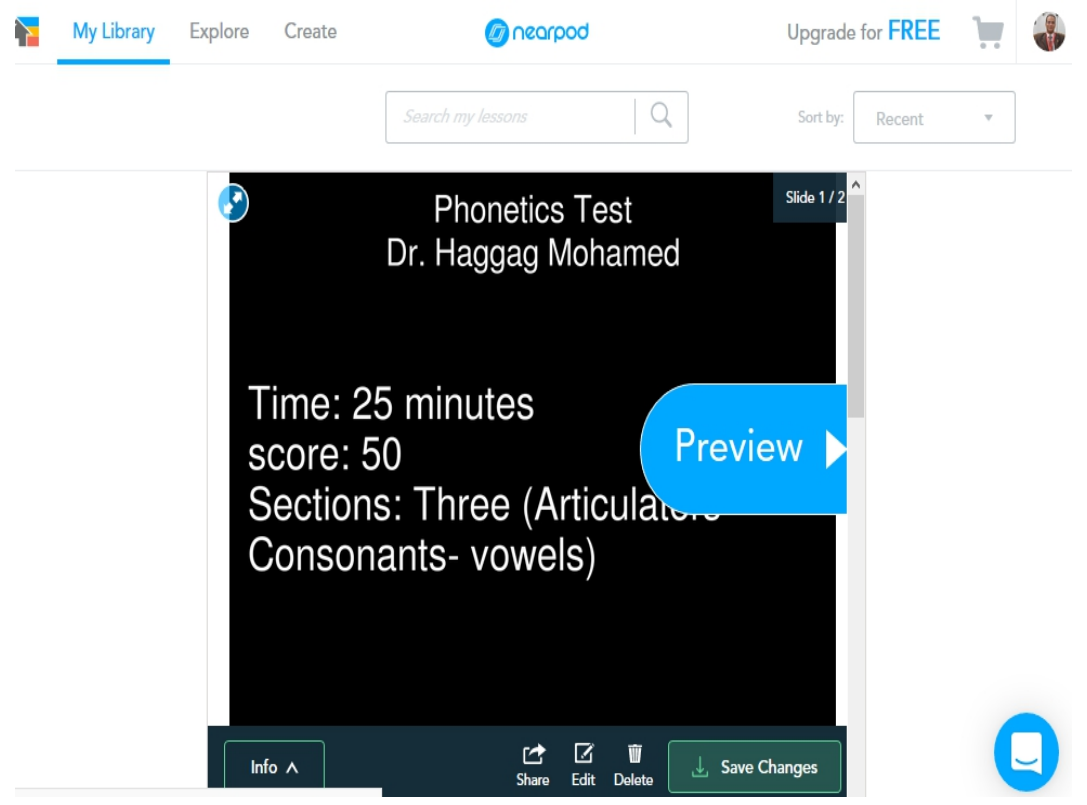

